\title{
The future outlook for Portuguese travel agents
}

\author{
A. GeOrge Assaf
}

Isenberg School of Management, University of Massachusetts-Amberst, 121 Presidents Drive, Amberst, MA 01003,USA.E-mail: assaf@bt.umass.edu.

\section{CARlos PESTANA BARros}

Instituto Superior de Economia e Gestão, Technical University of Lisbon, Rua Miguel Lupi 20, 1249-078 Lisbon, Portugal, and UECE (Research Unit on Complexity and Economics).E-mail: cbarros@iseg.utl.pt.

\section{LUIZ PINTO MACHADO}

Escola Profissional de Hotelaria e Turismo, Travessa Dos Piornais, São Martinho, 9000-246 Funchal, Madeira, Portugal.E-mail: luizpintomachado@bravacar.pt.

This paper adopts a three-stage procedure to measure and test the productivity and efficiency standings of Portuguese travel agents during 2005-2007. In the first stage, the authors use a bootstrapped Malmquist index approach to obtain estimates of total productivity growth. In the second stage, they obtain year-by-year efficiency scores, using a bootstrapped DEA model. A bootstrapped truncated regression is then adopted in the third stage to identify the covariates that explain technical efficiency. Results from a sample of 25 agents indicate that, on average, Portuguese agents experienced an increase in productivity over the period of the study. On the efficiency side, however, most travel agents were found to be operating at a high degree of inefficiency. Differences in productivity and efficiency between individual travel agents appeared to be related to factors such as market share and management style. The results are discussed and policy implications are derived.

Keywords: productivity; Portuguese travel agents; two-stage Malmquist index

Over the past three decades, the increased awareness about competition among travel agents has changed the focus from an almost exclusive concern with market share to the need to include productivity and efficiency explicitly in the decision support process (Bell and Morey, 1995; Anderson et al, 1999a,b, 
2000). This is not surprising as productive firms are able to maximize their outputs without incurring any extra input costs. Indirectly, a more productive process is also expected to translate into higher revenues, and consequently into a larger market share.

However, the importance of this topic is not well illustrated in the literature. A review of recent studies clearly indicates that little research has focused on analysing the productivity of travel agents. The available studies tend also to suffer from common methodological limitations which can affect the productivity and efficiency results. For example, Barros and Dieke (2008) have addressed the productivity of Portuguese travel agents recently, but their study used the traditional DEA method, which suffers from statistical limitations. In other related literature such as that on hotels, more studies have focused on the topic of productivity analysis, using simple and advanced methodologies and covering several international countries (Barros, 2006; Peypoch and Solonandrasana, 2006, 2008).

Acknowledging all these limitations, the focus in the present study is to introduce some of the most recent methodological innovations to analyse the productivity and efficiency of travel agents. In our application, we use a sample of Portuguese travel agents. Apart from the issue of data availability, the selection of Portugal is driven by the fact that this country has a strong reliance on tourism for the growth of its economy. The country is often described as one of the most attractive European and international tourist destinations, being visited in 2006 by around 12.8 million tourists. In terms of absolute size, tourism in this country ranks it among the top 25 countries worldwide.

Other trends related to the Portuguese and international travel agent industry also drive the motivation of this paper. In Portugal, for example, the need for high efficiency is justified by the high level of competition in the sector. This mainly followed the adoption of the EU's Single Market Programme (SMP), which facilitated the entrance of Spanish travel agents and, as a result, intensified the level of competition between Portuguese and foreign travel agents. Mergers and acquisitions were also observed in the Portuguese market as a reaction to the high level of competition.

In Portugal and other international countries, the travel agent industry is in a period of significant competition due to the low growth in domestic travel, the low growth in international visitor arrivals, the rapid growth of the Internet, low commissions on the sale of domestic airline tickets, the reduction in airline commission on international airline ticket sales and the high fuel prices.

Within all these current and emerging trends, performance evaluation therefore becomes an important issue. For strategy formulation, it is important to identify the factors that contribute to the performance of this industry. We address these two important issues in this paper. Performance-related studies on travel agents' literature tend to focus mainly on the efficiency of firms. Research on productivity growth is less common. Our paper contemplates these two types of linked research. In the first stage, we estimate the annual productivity growth of each travel agent and then, in the second stage, we provide yearly measures of efficiency scores. Productivity growth usually results from changes in efficiency or technology, and these two measures are also reported and discussed in the study. As a final stage, the study analyses the 
determinants of efficiency and productivity growth using second-stage regression modelling.

The methodology used in this study provides an innovation in the literature. In each of the three stages of the paper, we use the bootstrapping methodology to correct for the limitations of the data envelopment analysis (DEA) method, traditionally used to estimate measures of efficiency and productivity. More details on the bootstrap approach are provided in later sections. The paper is organized as follows. The next section provides the contextual setting and this is followed by a review of the literature. The two subsequent sections present the methodology and data used. The results are then presented and discussed and in the final section we offer our concluding remarks.

\section{Contextual setting}

Traditionally, travel agents help travellers make the best possible travel arrangements. They usually offer advice on destinations and make arrangements for transportation, hotel accommodation, car rental and tours for their clients. They are also the primary source of bookings for most major cruise lines. In addition, resorts and specialty travel groups use travel agents to promote travel packages to their clients.

The current role of travel agents is, however, gradually diminishing. Today, major threats to their role include the development of Internet booking websites. In Portugal, the fast penetration of foreign companies is also creating additional threats. For instance, the number of Portuguese travel agents increased by around 22.6\% between 2005 and 2009. The current market is also highly concentrated, where around $75 \%$ of the market share is restricted to a group of only 25 travel agents.

Table 1 presents more detailed characteristics of these agents. We can see from the table that the travel agency market is relatively concentrated, with a small number of agents having a high market share. Top Atlântico, Netviagens, Tagus and Wagonlit belong to the Banc Espirito Santo, as a result of acquisition. Star belongs to Sonae, a Portuguese conglomerate well known in the hypermarket sector and sells through the Sonae hypermarket network. Geotur belongs to the $R A R$, a Portuguese conglomerate group with strong interests in the sugar refining industry. Spanish agents are the Viajes Corte Inglês from the retailing company, Corte Ingles, and sell through the Corte Ingles retailing establishments, Escalatur from the Barcelo Group and Halcon, which together have a combined share of $5 \%$ of the Portuguese market; but this market share rises every year.

Thus, the market is highly concentrated and characterized by mergers and acquisitions. In other words, competition is high and each travel agent seeks to maintain its share and improve its productivity. In the following sections, we describe the literature review and the methodology used in the paper.

\section{Literature review}

Several studies in the past have analysed the rapidly changing role and 'disintermediation' of travel agents in the tourism/hospitality industries. The 
Table 1. Characteristics of Portuguese travel agents in 2007.

\begin{tabular}{|c|c|c|c|}
\hline Travel agent & Sales & Operational cost & Number of workers \\
\hline Top Atlântico & $197,500,177$ & $156,100,000$ & 510 \\
\hline Abreu & $167,777,367$ & $140,093,000$ & 434 \\
\hline Eloair (ex Elovia) & $110,774,606$ & $102,596,000$ & 287 \\
\hline HCT (ex Aviana) & $78,973,455$ & $116,054,000$ & 204 \\
\hline Star & $78,127,538$ & $68,515,000$ & 202 \\
\hline Geotur & $52,186,474$ & $65,183,000$ & 135 \\
\hline Worldtravel & $51,487,522$ & $55,827,000$ & 133 \\
\hline Wagonlit & $35,790,036$ & $35,385,000$ & 93 \\
\hline Atlantida & $33,512,657$ & $33,652,000$ & 87 \\
\hline Escalatur & $22,060,956$ & $36,828,000$ & 57 \\
\hline Corte Inglês & $17,658,948$ & $28,502,000$ & 45 \\
\hline Miltours & $17,506,197$ & $26,633,000$ & 45 \\
\hline Halcon Viagens & $14,283,381$ & $27,242,000$ & 37 \\
\hline Tagus & $13,770,740$ & $21,145,000$ & 36 \\
\hline AP Tours & $13,703,622$ & $9,481,000$ & 36 \\
\hline Travelstore & $11,843,993$ & $3,508,000$ & 30 \\
\hline Cosmos & $10,815,238$ & $3,768,000$ & 28 \\
\hline Paneuropa & $10,238,950$ & $4,837,000$ & 26 \\
\hline Bravatour & $9,279,627$ & $8,887,000$ & 24 \\
\hline Entremares & $9,144,234$ & $6,451,000$ & 24 \\
\hline Club Viajar & $8,726,483$ & $2,306,000$ & 23 \\
\hline Portimar & $8,542,487$ & $8,974,000$ & 22 \\
\hline Teles & $7,755,588$ & $8,448,000$ & 21 \\
\hline ACP & $7,752,116$ & $6,382,000$ & 21 \\
\hline Netviagens & $7,230,217$ & $8,095,000$ & 18 \\
\hline Mean & $39,857,704$ & $39,395,680$ & 103 \\
\hline Median & $14,283,381$ & $26,633,000$ & 37 \\
\hline Standard deviation & $50,977,809$ & $44,824,964$ & 131.7 \\
\hline
\end{tabular}

main threats stem from the rapid growth of the Internet, the reduced commissions on sales by airlines and the significant price-based competition among agents. Several strategies towards the future repositioning of travel agents have also been proposed by recent studies. In general, there is an agreement that travel agents remain a key component of the tourism/hospitality network. From the hotel perspective, travel agents are also still perceived to be an important intermediary.

The impact of travel agents on the image of a particular destination has also been analysed recently by Frias et al (2008). Their results indicated that destination image was poorer when tourists used the Internet to book their holiday than when they exclusively used travel agents. The authors further discuss that the information overload which results from the Internet might, in some cases, have a negative impact on the tourist perception of a particular destination. Other related studies have also stressed the continuing importance of travel agents in improving the tourist experience.

The recent literature has emphasized that it is important for travel agents to re-analyse their role in the current changes in the market. The focus should 
be mainly on embracing new technology and on extending the services on offer (Buhalis, 2000; Law et al, 2002). Some studies have also discussed the changing role from the hotel perspective. Tse (2003), for example, indicates that although hotels can develop their Internet profile to sell rooms at a cheaper price, they should focus on maintaining a 'win-win' arrangement with travel agents. This is because many travellers do not like to plan the trip themselves and still seek the help of travel agents. Thus, by continuing to work against travel agents, hotels risk loosing an important share of the market. Some other studies (Alamdari, 2002) have also highlighted the changing relationship between travel agents and airlines. It is argued that travel agents will always play an important role in ticket booking but, instead of restricting their activities to ticket selling, they need to provide a 'value-added service' to both individual and corporate customers. They need also to incorporate new and sophisticated technologies to stay ahead of the game.

The literature has clearly highlighted that the potential collapse of some travel agents is inevitable, especially for those operating on a smaller scale (Barros and Dieke, 2008; IBISWorld, 2009). Over the past few years, several mergers and acquisition have occurred, leaving small agents to compete in a much more difficult market. These small agents do not have a significant impact on the airlines' market share and lack the economies of scale and the financial resources to incorporate new technologies. In other industries such as hotels and airports (Barros and Dieke, 2008; Assaf, 2009) the impact of size was also tested and, in most cases, larger firms were found to be more efficient, due mainly to their economies of scale and saving power.

From the above literature, it is thus clear that recent studies have addressed several important aspects and trends facing the travel agent industry. In this paper, we extend the above literature by focusing on the performance analysis of travel agents. It is surprising that despite the financial and competition challenges facing the industry, only five studies so far have focused on the performance or efficiency analysis of travel agents: Bell and Morey (1995), Anderson et al (1999b), Barros and Matias (2006), Barros and Dieke (2007) and Köksal and Aksu (2007). The first two papers analysed corporate travel agents. Bell and Morey (1995) introduced a methodology to estimate the potential of a department to reduce its business travel costs. Anderson et al (1999b) have also provided answers regarding the minimum costs that need to be allocated to corporate travel agents, using as an output the number of trips booked by the agent.

In a more recent application, Köksal and Aksu (2007) evaluated the comparative operating efficiency of 24 international travel agents in the city of Antalya (Turkey). Travel agents were grouped into 'independently operating' and 'operating under a chain brand', for the purpose of testing the following hypothesis: 'Does the type of ownership of travel agents, operating independently or under a chain brand influence the unit's efficiency score?'. The authors selected the number of staff, annual expenses (US\$) and 'having service potential' as inputs, and the number of customers served as an output. 'Having service potential' is the short description of the question: 'How many customers could you have served with your existing service capacity in the current tourism year?'. Their DEA analysis provides evidence that the ownership type does not have a significant impact on the efficiency of travel agents. 
Another European application includes that of Barros and Matias (2006), which uses an econometric frontier model to evaluate the technical efficiency of a sample of Portuguese travel agents. They adopted a model similar to that of Anderson et al (1999b), but with a linear homogeneity cost function and a wider range of variables. Using similar data, Barros and Dieke (2007) analysed the productivity of a sample of travel agents operating in Portugal for the period 2000-2004. The changes in total productivity were broken down into technical change and technological change by means of a traditional Malmquist productivity index.

Apart from these studies, most other efficiency studies in the area were restricted to other sectors of the hospitality and tourism industries, such as hotels and restaurants. The above studies also suffer from common methodological limitations which might interfere strongly with the efficiency results. Discussing the Portuguese studies, for example, Barros and Matias (2006) used a stochastic cost frontier model, which focused mainly on cost efficiency but ignored the issue of technical efficiency, which was more in line with the management performance of travel agents. The use of stochastic frontier also requires a pre-assignment of the functional form of the stochastic frontier model, and this might sometimes affect the accuracy of the model estimation. Barros and Dieke (2007) focused on technical efficiency, but they used mainly the traditional Malmquist index. The authors adopted a second-stage Tobit regression, which again suffered from methodological limitations, as will be discussed later in the paper.

In the next sections, we provide more details on the main purpose of this paper, which focuses on offering a more advanced approach in assessing the efficiency and productivity of travel agents.

\section{Methodology}

In this study we follow a three-step approach to assess the performance of Portuguese travel agents. In the first step we use a bootstrapped Malmquist index approach to measure total productivity growth and decompose it into technical and efficiency components. In the second step we use a bootstrapped DEA model to measure the year-by-year efficiency scores. In the final step we analyse the external and environmental factors that might influence efficiency and productivity. In the following subsections we describe in detail each of these steps. We start with the description of efficiency measurement using DEA.

\section{Efficiency estimation - DEA}

Data envelopment analysis (DEA) is used to derive the efficiency estimates of Portuguese travel agents. The method is well established in the literature and has been tested across several areas of the literature such as hotels (Johns et al, 1997; Brown and Ragsdale, 2002; Reynolds, 2003; Barros and Dieke, 2008) and restaurants (Reynolds and Thompson, 2007). Given the rich literature available on this method, we focus here on the methodological formulation of DEA only. 
The method involves the use of a linear programming formulation to construct a non-parametric frontier over the data. Efficiency estimates are then derived relative to this surface. To illustrate, assume that there are data of known vectors of inputs and outputs of $L$ firms, the linear programming (LP) formulation that is solved for the $i$ th firm is as follows:

$$
\begin{array}{lll} 
& \max _{\theta, \lambda} \theta & \\
\text { st } \quad \theta y_{i m} \leq \sum_{k=1}^{L} \lambda_{k} y_{m k}, & m=1 \ldots, M, \\
\sum_{k=1}^{L} \lambda_{j} x_{k n} \leq x_{i n}, & n=1 \ldots, N, \\
\lambda_{i} \geq 0, & i=1 \ldots, L
\end{array}
$$

where $\mathbf{x}_{i}=\left(x_{i 1}, \ldots x_{i n} \ldots, x_{i N}\right)^{\prime} \in R_{+}^{N}$, and $\mathbf{y}_{i}=\left(y_{i 1}, \ldots y_{i m} \ldots, y_{i M}\right)^{\prime} \in R_{+}^{M}$ are the input and output vectors corresponding to firm $i, \lambda$ is an $L \times 1$ vector of weights and $\theta$ is a scalar. Note that $\theta$ will take a value greater than or equal to one and that $\theta-1$ is the proportional increase in outputs that could be achieved by the $i$ th firm, with input quantities held constant. The value $1 / \theta$ defines a technical efficiency (TE) score, which varies between zero and one. The above LP is solved $L$ times - once for each firm in the sample.

\section{Productivity growth estimation - Malmquist productivity index}

To measure whether the productivity of Portuguese travel agents has progressed or regressed over time, we use the Malmquist productivity index, which is a quantity index defined using the ratio of distance functions.

To define the Malmquist index, we start with a description of the distance function, which can be written as:

$$
d_{0}(x, y)=\min \{\theta:(y / \theta) \in \Psi(x)\}
$$

where $\Psi(x)$ is the production set which models the transformation of inputs $\mathbf{x} \in R_{+}^{N}$ into outputs $\mathbf{y} \in R_{+}^{M}$. Note that $d_{0}(x, y) \leq 1$ if and only if $(x, y) \in P(x)$.

The Malmquist index measures the total factor productivity (TFP) change between two data points by calculating the ratio of the distances of each data point relative to a common technology. Following Fare et al (1994), the index can be calculated between two periods, $t$ and $t+1$, as the geometric mean of the $t$ and $t+1$ indices:

$$
M I_{0}^{t, t+1}=\left[\frac{d_{0}^{t}\left(y^{t+1}, x^{t+1}\right) d_{0}^{t+1}\left(y^{t+1}, x^{t+1}\right)}{d_{0}^{t}\left(y^{t}, x^{t}\right) d_{0}^{t+1}\left(y^{t}, x^{t}\right)}\right]^{1 / 2}
$$

where $d_{0}^{t}\left(y^{t+1}, x^{t+1}\right)$ represents the distance from the period $t+1$ observation to the period $t$ technology. Improvements of productivity over time are signalled when $M I_{0}^{t, t+1}$ is larger than one, where declines in productivity are signalled when $M I_{0}^{t, t+1}$ is less than one. The index in (3) can also be decomposed further into two components: efficiency change and technological change as: 


$$
M I_{0}^{t, t+1}=\underbrace{\frac{d_{0}^{t+1}\left(y^{t+1}, x^{t+1}\right)}{d_{0}^{t}\left(y^{t}, x^{t}\right)}}_{\text {Efficiency change }}[\underbrace{\frac{d_{0}^{t}\left(y^{t+1}, x^{t+1}\right) d_{0}^{t}\left(y^{t}, x^{t}\right)}{d_{0}^{t+1}\left(y^{t+1}, x^{t+1}\right) d_{0}^{t+1}\left(y^{t}, x^{t}\right)}}_{\text {Technological change }}]^{1 / 2}
$$

where the first component in the above represents the efficiency change (that is, the change in airport location relative to the technology between the two periods) and the second component represents the technological change (that is, the change in technology location between the two periods). Note that it is possible to take the efficiency change measure in (4) and decompose it into scale and pure efficiency change components.

As indicated in (4), the estimation of the Malmquist index and its components requires the estimation of four distance functions: $d_{0}^{t}\left(y^{t}, x^{t}\right), d_{0}^{t+1}\left(y^{t+1}, x^{t+1}\right)$, $d_{0}^{t}\left(y^{t+1}, x^{t+1}\right)$ and $d_{0}^{t+1}\left(y^{t}, x^{t}\right)$. DEA is usually the common method used in the literature to estimate these distance functions. The method was illustrated in (1) and can be expressed in the case of $d_{0}^{t}\left(y^{t}, x^{t}\right)$, for example, as:

$$
\begin{aligned}
& {\left[d_{0}^{t}\left(y_{i}^{t}, x_{i}^{\dagger}\right)\right]^{-1}=\max \theta} \\
& \text { st } \quad \theta y_{i m}^{t} \leq \sum_{k=1}^{L} \lambda_{k}^{t} y_{m k}^{t}, \quad m=1 \ldots, M \text {, } \\
& \sum_{k=1}^{L} \lambda_{j}^{t} x_{k n}^{t} \leq x_{i n}^{t}, \quad n=1 \ldots, N, \\
& \lambda_{i}^{t} \geq 0, \quad i=1 \ldots, L
\end{aligned}
$$

where $\mathbf{x}_{i}^{t}=\left(x_{i 1}^{t}, \ldots x_{i n}^{t} \ldots, x_{i N}^{t}\right)^{\prime} \in R_{+}^{N}$, and $\mathbf{y}_{i}^{t}=\left(y_{i 1}^{t}, \ldots y_{i m}^{t} \ldots, y_{i M}^{t}\right)^{\prime} \in R_{+}^{M}$ are the input and output vectors corresponding to firm $i, i=1, \ldots, L$, in period $t$, respectively. The distance function $d_{0}^{t+1}\left(x^{t+1}, y^{t+1}\right)$ can also be computed in similar fashion by substituting $t+1$ for $t$.

Finally, $D_{0}^{t}\left(x^{t+1}, y^{t+1}\right)$ can be computed as follows:

$$
\begin{array}{lll} 
& {\left[d_{0}^{t}\left(y_{i}^{t+1}, x_{i}^{t+1}\right]^{-1}=\max \right.} & \theta \\
\text { st } \quad & \theta y_{i m}^{t+1} \leq \sum_{k=1}^{L} \lambda_{k}^{t} y_{m k}^{t}, & m=1 \ldots, M, \\
\sum_{k=1}^{L} \lambda_{j}^{t} x_{k n}^{t} \leq x_{i n}^{t+1}, & n=1 \ldots, N, \\
\lambda_{i}^{t} \geq 0, & i=1 \ldots, L
\end{array}
$$

Note that $d_{0}^{t+1}\left(y_{i}^{t}, x_{i}^{*}\right)$ can be computed in similar fashion by substituting $t+1$ for $t$. For more detail on the Malmquist index, refer to Coelli et al (2005).

\section{The DEA Bootstrap}

As mentioned before, DEA is a linear programming methodology and thus has no statistical properties or account for measurement error. This will frequently create problems, seeing that measurement errors and uncertainty are common 
in observed data. Simar and Wilson (1998, 1999 and 2000) have recently shown that it is possible to obtain statistical properties via the use of the 'bootstrap' approach. When applied to DEA, the bootstrap allows the construction of confidences intervals, thus making it possible to obtain statistical properties of the efficiency estimates and also perform some hypotheses testing.

The basic idea of bootstrapping is to approximate the distribution of the estimator via resampling and recalculation of the parameter of interest, which in our case is the DEA efficiency score. Specifically, the bootstrap procedure can be formulated as follows:

(1) Compute the efficiency score $\hat{\theta}_{i}$ for each firm $i=1, \ldots, L$, following the linear programming model in (1).

(2) Generate a random sample of size $L$ from $\left\{\hat{\theta}_{i} ; i=1, \ldots, L\right\}$, providing $\left\{\theta_{1 b}^{*}, \ldots, \theta_{L b}^{*}\right\}$, following the kernel density estimation and reflection method.

(3) Compute a pseudo data set $\left\{\left(\mathbf{x}_{i b}^{*}, \mathbf{y}_{i}\right), i=1, \ldots, L\right\}$ to form the reference bootstrap technology.

(4) Use this pseudo data set to obtain the DEA bootstrap estimates of the efficiency scores, $\hat{\theta}_{i b}^{*}$.

(5) Repeat all steps $B$ times to generate a set of estimates $\left\{\hat{\theta}_{i b}^{*}, b=1, \ldots B\right\}$.

The mean of the bootstrap estimator could then be used as an approximation of the DEA estimator. This is not, however, bias free. The bootstrap estimate of the DEA estimator bias is given by

$$
\hat{b i a s}_{i}=\frac{1}{B} \sum_{b=1}^{B} \hat{\theta}_{i b}^{*}-\hat{\theta}_{i}
$$

where the term on the right-hand side represents the mean of the bootstrap efficiency score and the second is the original DEA estimate of the efficiency score. This estimation of confidence intervals also follows the bootstrap estimation. In this paper, we construct the confidence intervals using the bias corrected approach suggested by Simar and Wilson (1998). This method improves on the simple percentile method traditionally used to obtain confidence intervals. The argument is that DEA estimators are biased in small samples, so shifting the bounds of the interval by the factors $2 * b i \hat{s}_{i}^{*}$ will ensure that the empirical bootstrap distribution centres on the bias corrected estimate $\tilde{\theta}_{i}=\hat{\theta}_{i}-$ bias $_{i}^{*}$. For more specific details, refer to Simar and Wilson (1998).

\section{The Malmquist productivity index bootstrap}

The bootstrapping procedure discussed in the DEA context can also be extended to determine the statistical properties of the Malmquist index. The only difference is that the Malmquist index involves a panel structure which gives rise to possible temporal correlation. Simar and Wilson (1999) proposed a consistent method using a bivariate kernel density estimate that accounted for the temporal correlation via the covariance matrix of data from adjacent years. For more details about the Malmquist index bootstrap approach, refer to Simar and Wilson (1999). 


\section{Accounting for environmental variables}

As well as obtaining productivity and efficiency scores, we also used a bootstrapped truncated regression approach to determine the impact of external environmental variables on efficiency. These variables are outside the control of producers, but can still impact indirectly on efficiency. A common approach in the literature is to use a Tobit regression, whereby efficiency and productivity scores are first calculated and then regressed on a set of environmental variables. However, such approach is invalid due to the dependency problem of efficiency scores, which violates the regression assumption.

In this paper, we overcome the traditional limitations in the literature by using the double bootstrapping procedure, in which the bootstrap estimators are substituted from the estimators in the regression stage to calculate the standard error of the estimates. Barros and Dieke (2007) recently applied a second-stage bootstrap on travel agents, but they used a Tobit regression instead of a truncated regression model. The use of a Tobit model was criticized by Simar and Wilson (2007), as the efficiency scores are truncated rather than censored. Specifically, the Tobit specification is motivated usually by the assumption that several efficiency values are equal to one. However, the underlying assumption of the second-stage regression efficiency model does not contain this property. Simar and Wilson (2007) have also compared the results from the Tobit and truncated regression and provided evidence that the truncated regression is more accurate and consistent. For more details on these issues, refer to Simar and Wilson (2007). The specific details of the bootstrap procedure applied to the truncated regression model are also available in Simar and Wilson (2007).

\section{Data}

The estimation of the DEA and Malmquist index in this study was based on several input and output variables related to the operational characteristics of Portuguese travel agents. The related literature was also used as guidance in confirming the list of inputs and outputs selected. On the inputs side, we used the number of full-time equivalent employees, operational costs (excluding labour costs) and capital (measured as book value of premises). Variables selected as outputs included total sales and total earnings. Table 2 provides some descriptive statistics of the data. The sources of data collection included the annual report published by the major Portuguese newspaper, Diario de Noticias, financial reports of each company and direct information obtained via interview with the managers of some travel agents.

To determine the sources of productivity and efficiency changes, we selected three environmental variables; namely, market share, management style and type of ownership. The market share is a reflection of size and aims to capture whether size differences between travel agents contribute to variations in efficiency and productivity scores. In general, it is hypothesized that larger size is associated with higher performance and economies of scale (Barros and Dieke, 2008; Assaf, 2009). The management style variable was measured by a dummy variable differentiating between those travel agents that belonged to 
Table 2. Descriptive statistics of the data.

\begin{tabular}{lccccc}
\hline & Mean & Median & Std dev & Min & Max \\
& & & & & \\
Number of workers & 92.15 & 37.00 & 118.05 & 3.00 & 510.00 \\
Operational costs & $32,588,904$ & $14,528,000$ & $42,602,198$ & $1,129,000$ & $199,116,000$ \\
Book value of assets & $7,411,713$ & $3,090,895$ & $9,588,865$ & 177,000 & $43,523,637$ \\
Sales & $33,632,311$ & $14,027,061$ & $43,194,024$ & 804,000 & $197,500,177$ \\
Earning (euros) & 42,000 & 19,000 & 35.00 & 15,000 & $1,940,000$ \\
\hline
\end{tabular}

a group and those that were owned independently. This hypothesis was tested mainly on hotels (Barros and Dieke, 2008) and, in general, researchers found that group membership contributed most to a higher efficiency. This result is also expected to hold in the case of travel agents, as they operate in a fashion somehow similar to hotels. Finally, in terms of the ownership variable, we used a dummy variable to differentiate between nationally and foreign owned travel agents.

\section{Results}

\section{Productivity growth}

The bootstrap estimates of the changes in productivity, efficiency and technology are reported in Tables $3-5$. In the first 7 columns of each table, we report the changes between each consecutive year, while the last column reports the changes for the whole sample period. The average of each selected period is reported in the last row of each table. In each table, we also report whether the changes in productivity or its components are significantly different from unity. The degree of significance is based on the confidence intervals. For space limitation, we do not report the confidence intervals here, but the main hypothesis states that if the confidence interval excludes unity, then the corresponding change is significantly different from unity.

Table 3 indicates that, on average, productivity is higher than 1 for all periods in the sample, except for the 2005-2006 period. In the 2000-2007 period, the average increase in productivity is around $20.11 \%$. However, looking at individual agents, it is clear that several agents have not experienced a significant increase in productivity. In some cases, small agents such as Portimar, Teles, ACP and Netviagens have experienced a significant decrease in productivity.

In Tables 4 and 5, we also decomposed the productivity changes into efficiency and technical changes. It is clear that for some agents, efficiency and technology are both contributing to productivity change. However, in terms of contribution to growth, technological change appears to have a stronger contribution, illustrated mainly by a $26.51 \%$ technical growth over the 2000 2007 period, while efficiency has decreased slightly but not at a significant level. From investigating individual periods, it is also clear that more travel agents experienced significant technical growth than efficiency growth. For instance, between 2006 and 2007, only 1 travel agent experienced significant efficiency growth, while in the same period, 14 travel agents experienced 
Table 3. Bootstrapped productivity changes.

\begin{tabular}{|c|c|c|c|c|c|c|c|c|}
\hline Travel agent & $\begin{array}{l}2000- \\
2001\end{array}$ & $\begin{array}{l}2001- \\
2002\end{array}$ & $\begin{array}{l}2002- \\
2003\end{array}$ & $\begin{array}{l}2003- \\
2004\end{array}$ & $\begin{array}{l}2004- \\
2005\end{array}$ & $\begin{array}{l}2005- \\
2006\end{array}$ & $\begin{array}{l}2006- \\
2007\end{array}$ & $\begin{array}{l}2000- \\
2007\end{array}$ \\
\hline Top Atlântico & $1.0160 * *$ & $1.0110 * *$ & $1.9950 * *$ & $1.2540 * *$ & $1.0230 * *$ & 1.0140 & $1.0340 * *$ & $1.7685 * *$ \\
\hline Abreu & $1.0970 * *$ & $1.0070 * *$ & $1.0370 * *$ & 0.9990 & 1.0000 & 0.9990 & $1.0709 * *$ & $1.2427 * *$ \\
\hline \multicolumn{9}{|l|}{ Eloair } \\
\hline \multicolumn{9}{|l|}{ HCT } \\
\hline (ex Aviana) & $1.0130 * *$ & $1.0040 * *$ & 1.0020 & $1.0020 * *$ & $1.0018 * *$ & 1.0000 & $1.0700 * *$ & 1.0721 \\
\hline Star & $1.0220 * *$ & $1.0050 * *$ & $1.0710 * *$ & $1.0030 * *$ & $1.0019 * *$ & 1.0000 & $1.0700 * *$ & $1.2004 * *$ \\
\hline Geotur & $1.0500 * *$ & $1.0040 * *$ & 1.0010 & 1.0000 & $1.0020 * *$ & 1.0000 & $1.0700 * *$ & 1.0738 \\
\hline Worldtravel & 0.9910 & $1.0110 * *$ & $1.0040 * *$ & $1.0090 * *$ & 1.0010 & 0.9990 & $1.0700 * *$ & 1.0714 \\
\hline Wagonlit & 1.0120 & $1.0040 * *$ & 0.9960 & 1.0000 & $1.0040 * *$ & 0.9970 & $1.0699 * *$ & $1.1173 * *$ \\
\hline Atlantida & $1.0030 * *$ & 1.0020 & $1.0970 * *$ & $0.9980 * *$ & 1.0000 & 0.9950 & $1.0700 * *$ & 1.0935 \\
\hline Escalatur & $0.9860 * *$ & $1.0200 * *$ & 0.9980 & $0.9920 * *$ & $0.9940 * *$ & 1.0120 & $1.0701 * *$ & 1.0664 \\
\hline Corte Inglês & $1.0120 * *$ & $1.0120 * *$ & $1.0070 * *$ & $0.9970 * *$ & $1.0028 * *$ & $1.0070 * *$ & $1.0700 * *$ & $1.0912 * *$ \\
\hline Miltours & $1.0170 * *$ & 0.9980 & $1.0130 * *$ & $0.9860 * *$ & $1.0030 * *$ & $1.0070 * *$ & $1.0698 * *$ & $1.0686 * *$ \\
\hline \multicolumn{9}{|l|}{ Halcon } \\
\hline Viagens & $0.9980 * *$ & $1.0290 * *$ & $1.7530 * *$ & $0.8850 * *$ & $0.9930 * *$ & $1.0030 * *$ & $1.0700 * *$ & $1.0857 * *$ \\
\hline Tagus & $1.0220 * *$ & 1.0030 & $1.9370 * *$ & $0.9740 * *$ & $0.9910 * *$ & $1.0020 * *$ & $1.0700 * *$ & 1.0678 \\
\hline AP Tours & $1.0280 * *$ & $1.0130 * *$ & $1.7550 * *$ & $0.9790 * *$ & $0.9910 * *$ & $1.0020 * *$ & $1.0700 * *$ & $1.2760 * *$ \\
\hline Travelstore & $1.0150 * *$ & $1.0760 * *$ & $1.4840 * *$ & $1.0450 * *$ & $1.0140 * *$ & $0.9940 * *$ & $1.0680 * *$ & $2.0966 * *$ \\
\hline Cosmos & $0.9790 * *$ & $1.0310 * *$ & $1.4880 * *$ & 1.0060 & $1.0110 * *$ & $0.9930 * *$ & $1.0670 * *$ & $1.7705 * *$ \\
\hline Paneuropa & $1.0220 * *$ & 1.0080 & $1.4170 * *$ & $1.0090 * *$ & $1.0080 * *$ & $0.9900 * *$ & $1.0680 * *$ & 1.0661 \\
\hline Bravatour & 0.9990 & $1.0330 * *$ & 0.9770 & $1.0180 * *$ & $1.0040 * *$ & $0.9880 * *$ & $1.0700 * *$ & 1.0809 \\
\hline Entremares & $0.9987 * *$ & $1.0260 * *$ & 0.9420 & $1.0150 * *$ & $1.0040 * *$ & $0.9870 * 8$ & $1.0690 * *$ & $1.2167 * *$ \\
\hline Club Viajar & $0.9710 * *$ & $1.0480 * *$ & $1.9810 * *$ & 0.9970 & $1.0020 * *$ & $0.9770 * *$ & $1.0690 * *$ & 1.0135 \\
\hline Portimar & $1.0100 * *$ & 0.9990 & $1.1510 * *$ & $1.0320 * *$ & 1.0000 & $0.9830 * *$ & $1.0690 * *$ & $0.9634 * *$ \\
\hline Teles & 1.0270 & $1.0130 * *$ & $1.0120 * *$ & $0.9610 * *$ & 0.9980 & $0.9820 * *$ & $1.0700 * *$ & $0.9389 * *$ \\
\hline $\mathrm{ACP}$ & 1.0290 & 1.0010 & $1.1580 * *$ & $0.9490 * *$ & 0.9980 & $0.9800 * *$ & $1.0680 * *$ & 0.9363 \\
\hline Netviagens & $1.0420 * *$ & $1.1240 * *$ & 0.9210 & $1.0590 * *$ & $0.9920 * *$ & $1.0300 * *$ & $1.0680 * *$ & 1.0410 \\
\hline \multicolumn{9}{|l|}{ Aritbmetic } \\
\hline mean & $1.1772 * *$ & $1.0193 * *$ & $1.3679 * *$ & $1.0467 * *$ & 1.0016 & 0.9976 & $1.0680 * *$ & $1.2011 * *$ \\
\hline
\end{tabular}

Note: **Significant change at the $95 \%$ confidence level.

technical growth. Factors that might have led to these findings, as well as the sources of productivity growth, are provided in the discussion.

\section{Efficiency}

In Table 6, we provide the bootstrapped technical efficiency scores. It is true that the Malmquist index indicates whether efficiency has progressed or regressed over time; however, it does not reflect the technical efficiency standing of each travel agent (a travel agent might, for example, experience efficiency growth, but still operate at a low efficiency rate). The efficiency results are illustrated for each year and the mean of the industry is provided in the last column of Table 6. For the sake of brevity, we do not report the original efficiency scores, but we rely mainly on the bootstrapped efficiency scores, due to their statistical advantage, as discussed in the subsection on the DEA bootstrap. 
Table 4. Bootstrapped efficiency changes.

\begin{tabular}{|c|c|c|c|c|c|c|c|c|}
\hline Travel agent & $\begin{array}{l}2000- \\
2001\end{array}$ & $\begin{array}{l}2001- \\
2002\end{array}$ & $\begin{array}{l}2002- \\
2003\end{array}$ & $\begin{array}{l}2003- \\
2004\end{array}$ & $\begin{array}{l}2004- \\
2005\end{array}$ & $\begin{array}{l}2005- \\
2006\end{array}$ & $\begin{array}{l}2006- \\
2007\end{array}$ & $\begin{array}{l}2000- \\
2007\end{array}$ \\
\hline Top Atlântico & 1.0000 & 1.0000 & 1.0000 & 1.0000 & 1.0000 & 1.0000 & 1.0000 & 1.0000 \\
\hline Abreu & 1.0000 & 1.0000 & $0.9980 * *$ & 1.0010 & 1.0000 & 0.9980 & 1.0000 & 0.9979 \\
\hline \multicolumn{9}{|l|}{ Eloair (ex } \\
\hline Elovia) & 1.0020 & 1.0000 & $0.9760 * *$ & $1.0220 * *$ & 1.0010 & 0.9970 & 1.0000 & 0.9976 \\
\hline \multicolumn{9}{|l|}{ HCT (ex } \\
\hline Aviana) & 1.0000 & $1.0030 * *$ & $0.9460 * *$ & $1.0540 * *$ & 1.0020 & 0.9990 & 1.0000 & 1.0003 \\
\hline Star & 0.9980 & $1.0040 * *$ & $0.9450 * *$ & $1.0550 * *$ & 1.0010 & 0.9980 & 1.0002 & 0.9988 \\
\hline Geotur & $1.0040 * *$ & $1.0030 * *$ & $0.9090 * *$ & $1.0940 * *$ & 1.0010 & 0.9990 & 1.0000 & 1.0013 \\
\hline Worldtravel & 0.9900 & $1.0100 * *$ & $0.8980 * *$ & $1.1110 * *$ & 1.0000 & 0.9980 & 1.0000 & 0.9953 \\
\hline Wagonlit & 1.0110 & $1.0040 * *$ & $0.8810 * *$ & $1.1230 * *$ & 1.0010 & 0.9960 & .0001 & 1.0018 \\
\hline Atlantida & $1.0000 * *$ & $1.0020 * *$ & $0.8890 * *$ & $1.1200 * *$ & 0.9980 & $0.9940 * *$ & 1.0000 & $0.9899 * *$ \\
\hline Escalatur & 0.9840 & $1.0190 * *$ & $0.8880 * *$ & $1.1110 * *$ & 0.9900 & $1.0120 * *$ & 1.0000 & $0.9907 * *$ \\
\hline Corte Inglês & 1.0010 & $1.0120 * *$ & $0.8920 * *$ & $1.1140 * *$ & $0.9970 * *$ & $1.0070 * *$ & 1.0000 & 1.0115 \\
\hline Miltours & 1.0000 & 1.0000 & $0.8950 * *$ & $1.1010 * *$ & 0.9970 & $1.0070 * *$ & 1.0000 & $0.9898 * *$ \\
\hline \multicolumn{9}{|l|}{ Halcon } \\
\hline Viagens & 0.9930 & $1.0320 * *$ & 1.0000 & 0.9900 & 0.9860 & 1.0030 & 1.0003 & 1.0035 \\
\hline Tagus & $1.0160 * *$ & 1.0000 & $0.9230 * *$ & $1.0650 * *$ & $0.9840 * *$ & 1.0020 & 1.0000 & $0.9852 * *$ \\
\hline AP Tours & 1.0270 & $1.0020 * *$ & $0.9070 * *$ & $1.0780 * *$ & $0.9838 * *$ & 1.0020 & 1.0000 & $0.9926 * *$ \\
\hline Travelstore & $1.0130 * *$ & $1.0710 * *$ & $0.8890 * *$ & $1.1250 * *$ & 1.0000 & 1.0000 & 1.0001 & 1.0852 \\
\hline Cosmos & $0.9750 * *$ & $1.0300 * *$ & $0.9010 * *$ & $1.0890 * *$ & 0.9990 & 0.9980 & 0.9990 & 0.9814 \\
\hline Paneuropa & $1.0120 * *$ & $1.0100 * *$ & $0.9010 * *$ & $1.1110 * *$ & 1.0000 & 0.9940 & 1.0000 & $1.0661 * *$ \\
\hline Bravatour & 0.9910 & $1.0280 * *$ & $0.8770 * *$ & $1.1270 * *$ & 0.9970 & $0.9860 * *$ & 1.0003 & 0.9889 \\
\hline Entremares & 0.9960 & $1.0040 * *$ & $0.8670 * *$ & $1.1230 * *$ & 0.9970 & $0.9870 * *$ & 1.0010 & $0.9584 * *$ \\
\hline Club Viajar & 0.9620 & $1.0390 * *$ & $0.9450 * *$ & $1.0430 * *$ & $0.9930 * *$ & $0.9820 * *$ & $1.0020 * *$ & 1.0135 \\
\hline Portimar & 1.0000 & 1.0000 & $0.8760 * *$ & $1.1420 * *$ & $0.9930 * *$ & $0.9800 * *$ & 1.0000 & $0.9729 * *$ \\
\hline Teles & $1.0170 * *$ & $1.0130 * *$ & $0.8990 * *$ & $1.0630 * *$ & $0.9910 * *$ & $0.9760 * *$ & 1.0000 & 1.0000 \\
\hline $\mathrm{ACP}$ & 1.0130 & 1.0000 & $0.9100 * *$ & $1.0500 * *$ & $0.9910 * *$ & $0.9780 * *$ & 1.0010 & $0.9363 * *$ \\
\hline Netviagens & 1.0100 & $1.1000 * *$ & $0.8500 * *$ & $1.1720 * *$ & $0.9850 * *$ & $1.0200 * *$ & 1.0000 & 1.0015 \\
\hline \multicolumn{9}{|l|}{ Arithmetic } \\
\hline mean & $1.1606 * *$ & 1.0154 & $0.9145 * *$ & $1.0834 * *$ & 0.9955 & $0.9965 * *$ & 1.0001 & 0.9984 \\
\hline
\end{tabular}

Note: **Significant change at the $95 \%$ confidence level.

The results illustrate clearly that many Portuguese travel agents are reasonably highly efficient. In 2007, the average efficiency level was around $85.06 \%$, which indicated that Portuguese travel agents were around $15.00 \%$ away from achieving the frontier of best practices. It is also noticed clearly that small agents such as Club Viajar, Portimar, Teles, ACP and Netviagens have a lower efficiency score than larger agents, with the gap between the largest and the smallest agent (Top Atlântico and Netviagens) at around 20\%. More implications of these findings are provided in the discussion.

\section{Second-stage truncated regressions}

As discussed previously, in order to analyse the impact of environmental factors on efficiency and productivity growth, we regressed the Malmquist index and 
Table 5. Bootstrapped technical changes.

\begin{tabular}{|c|c|c|c|c|c|c|c|c|}
\hline Travel agent & $\begin{array}{l}2000- \\
2001\end{array}$ & $\begin{array}{l}2001- \\
2002\end{array}$ & $\begin{array}{l}2002- \\
2003\end{array}$ & $\begin{array}{l}2003- \\
2004\end{array}$ & $\begin{array}{l}2004- \\
2005\end{array}$ & $\begin{array}{l}2005- \\
2006\end{array}$ & $\begin{array}{l}2006- \\
2007\end{array}$ & $\begin{array}{l}2000- \\
2007\end{array}$ \\
\hline Top Atlântico & 1.0160 & $1.0110 * *$ & $1.9950 * *$ & $2.2540 * *$ & $1.0230 * *$ & 1.0140 & $1.0340 * *$ & $1.7685 * *$ \\
\hline Abreu & $1.0970 * *$ & $1.0070 * *$ & 1.0390 & 0.9980 & 1.0000 & 1.0010 & $1.0700 * *$ & $1.2452 * *$ \\
\hline \multicolumn{9}{|l|}{ Eloair (ex } \\
\hline Elovia) & $1.0880 * *$ & $1.0010 * *$ & 1.0250 & $0.9770 * *$ & 1.0000 & 1.0010 & $1.0700 * *$ & $1.0714 * *$ \\
\hline \multicolumn{9}{|l|}{$\operatorname{HCT}(\mathrm{ex}$} \\
\hline Aviana) & 1.0130 & $1.0010 * *$ & $1.0590 * *$ & $0.9510 * *$ & 1.0011 & 1.0010 & $1.0700 * *$ & $1.0718 * *$ \\
\hline Star & 1.0240 & $1.0010 * *$ & $1.1340 * *$ & $0.9510 * *$ & 1.0009 & 1.0010 & $1.0700 * *$ & $1.2017 * *$ \\
\hline Geotur & 1.0460 & 1.0000 & $1.1000 * *$ & $0.9150 * *$ & 1.0010 & 1.0010 & $1.0700 * *$ & 1.0724 \\
\hline Worldtravel & 1.0000 & $1.0013 * *$ & $1.1180 * *$ & $0.9090 * *$ & 1.0020 & 1.0010 & $1.0700 * *$ & $1.0764 * *$ \\
\hline Wagonlit & 1.0010 & 0.9990 & $1.1300 * *$ & $0.8900 * *$ & 1.0020 & 1.0010 & $1.0700 * *$ & $1.1153 * *$ \\
\hline Atlantida & 1.0020 & 1.0000 & $1.2330 * *$ & $0.8910 * *$ & 1.0030 & 1.0010 & $1.0700 * *$ & $1.1046 * *$ \\
\hline Escalatur & 1.0030 & $1.0010 * *$ & $1.1240 * *$ & $0.8940 * *$ & 1.0040 & 1.0000 & $1.0700 * *$ & $1.0764 * *$ \\
\hline Corte Inglês & $1.0110 * *$ & 1.0000 & $1.1290 * *$ & $0.8960 * *$ & $1.0060 * *$ & 1.0000 & $1.0700 * *$ & $1.0788 * *$ \\
\hline Miltours & $1.0170 * *$ & $0.9980 * *$ & $1.1330 * *$ & $0.8958 * *$ & $1.0060 * *$ & 1.0000 & $1.0700 * *$ & $1.0795 * *$ \\
\hline \multicolumn{9}{|l|}{ Halcon } \\
\hline Viagens & 1.0040 & $0.9980 * *$ & $1.7530 * *$ & $0.8940 * *$ & $1.0070 * *$ & 1.0000 & $1.0700 * *$ & $1.0818 * *$ \\
\hline Tagus & $1.0060 * *$ & $1.0030 * *$ & $2.0970 * *$ & $0.9140 * *$ & $1.0070 * *$ & 1.0000 & $1.0700 * *$ & $1.0837 * *$ \\
\hline AP Tours & 1.0010 & $1.0110 * *$ & $1.9340 * *$ & $0.9080 * *$ & $1.0070 * *$ & 1.0000 & $1.0700 * *$ & $1.2850 * *$ \\
\hline Travelstore & 1.0030 & $1.0040 * *$ & $1.6690 * *$ & $0.9290 * *$ & $1.0140 * *$ & 0.9940 & $1.0680 * *$ & 1.0100 \\
\hline Cosmos & 1.0040 & $1.0010 * *$ & $1.6510 * *$ & $0.9240 * *$ & $1.0120 * *$ & 0.9950 & $1.0680 * *$ & $1.8038 * *$ \\
\hline Paneuropa & $1.0100 * *$ & 0.9990 & $1.5730 * *$ & $0.9080 * *$ & 1.0079 & 0.9960 & $1.0690 * *$ & 1.0000 \\
\hline Bravatour & 1.0080 & $1.0050 * *$ & $1.1140 * *$ & $0.9040 * *$ & $1.0080 * *$ & 1.0020 & $1.0700 * *$ & $1.0929 * *$ \\
\hline Entremares & 0.9940 & $1.0220 * *$ & $1.0860 * *$ & $0.9035 * *$ & $1.0081 * *$ & 1.0000 & $1.0690 * *$ & $1.2695 * *$ \\
\hline Club Viajar & $1.0100 * *$ & $1.0080 * *$ & $2.0950 * *$ & $0.9570 * *$ & $1.0090 * *$ & 0.9950 & $1.0670 * *$ & 1.0000 \\
\hline Portimar & $1.0100 * *$ & 0.9990 & $1.3140 * *$ & $0.9039 * *$ & $1.0070 * *$ & 1.0030 & $1.0690 * *$ & $1.0930 * *$ \\
\hline Teles & 1.0090 & 1.0000 & $1.1250 * *$ & $0.9033 * *$ & $1.0069 * *$ & 1.0060 & $1.0700 * *$ & $0.9389 * *$ \\
\hline $\mathrm{ACP}$ & $1.0160 * *$ & $1.0010 * *$ & $1.2730 * *$ & $0.9035 * *$ & $1.0068 * *$ & 1.0030 & $1.0670 * *$ & 1.0000 \\
\hline Netviagens & 1.0040 & $1.0220 * *$ & 1.0830 & $0.9039 * *$ & $1.0070 * *$ & $1.0100 * *$ & $1.0680 * *$ & 1.0398 \\
\hline \multicolumn{9}{|l|}{ Arithmetic } \\
\hline mean & $1.0159 * *$ & 1.0037 & $1.4794 * *$ & $0.9712 * *$ & $1.0063 * *$ & 1.0010 & $1.0680 * *$ & $1.2651 * *$ \\
\hline
\end{tabular}

Note: **Significant change at the $95 \%$ confidence level.

efficiency measures on three environmental variables, using a bootstrapped truncated regression model. The models can be illustrated as follows:

$$
\hat{M} I_{i t}^{*} \mid \hat{\theta}_{i t}^{*}=\beta_{0}+\beta_{1} \text { Share }_{i t}+\beta_{2} \text { Group }_{i t}+\beta_{3} \text { Foreign }_{i t}+\varepsilon
$$

where dependent variables in the two separate regression models are total factor productivity $\left.\hat{\mathrm{M}} I_{i t}^{*}\right)$ and the bootstrapped efficiency score $\left(\hat{\theta}_{i t}^{*}\right)$. Share ${ }_{i t}$, Group $_{i t}$ and Foreign $_{i t}$ are the explanatory variables representing market share, group membership and foreign ownership. The results based on 2,000 bootstrap iterations are illustrated in Table 7. It is clear that the market share variable has a positive influence on efficiency and productivity growth. This result is expected, given that large market share is associated with more revenues, stronger economies of scale and more market connectivity. 
Table 6. Bootstrapped DEA efficiency scores.

\begin{tabular}{lllllllll}
\hline Travel agent & 2000 & 2001 & 2002 & 2003 & 2004 & 2005 & 2006 & 2007 \\
Top Atlântico & 0.9155 & 0.9130 & 0.9108 & 0.8679 & 0.9040 & 0.9320 & 0.9330 & 0.9080 \\
Abreu & 0.9133 & 0.9113 & 0.9119 & 0.9122 & 0.9080 & 0.9040 & 0.8980 & 0.9020 \\
Eloair (ex Elovia) & 0.9141 & 0.9129 & 0.9109 & 0.9161 & 0.9140 & 0.9150 & 0.9130 & 0.9170 \\
HCT (ex Aviana) & 0.8975 & 0.8992 & 0.9003 & 0.9061 & 0.9070 & 0.9100 & 0.9110 & 0.8750 \\
Star & 0.8984 & 0.8988 & 0.9029 & 0.9002 & 0.8970 & 0.9000 & 0.9020 & 0.9000 \\
Geotur & 0.8820 & 0.8851 & 0.8827 & 0.8889 & 0.8880 & 0.8930 & 0.8940 & 0.9570 \\
Worldtravel & 0.8854 & 0.8729 & 0.8762 & 0.8821 & 0.8860 & 0.8890 & 0.8910 & 0.9070 \\
Wagonlit & 0.8769 & 0.8841 & 0.8726 & 0.8752 & 0.8690 & 0.8710 & 0.8700 & 0.8810 \\
Atlantida & 0.8846 & 0.8844 & 0.8744 & 0.8774 & 0.8680 & 0.8670 & 0.8610 & 0.8740 \\
Escalatur & 0.8911 & 0.8756 & 0.8821 & 0.8869 & 0.8780 & 0.8720 & 0.8830 & 0.7900 \\
Corte Inglês & 0.8815 & 0.8772 & 0.8744 & 0.8924 & 0.8890 & 0.8900 & 0.8980 & 0.9010 \\
Miltours & 0.8905 & 0.8774 & 0.8865 & 0.8936 & 0.8800 & 0.8820 & 0.8900 & 0.8801 \\
Halcon Viagens & 0.8774 & 0.8744 & 0.8739 & 0.9513 & 0.8900 & 0.8820 & 0.8840 & 0.8960 \\
Tagus & 0.8882 & 0.7066 & 0.8947 & 0.8590 & 0.8810 & 0.8710 & 0.8750 & 0.8880 \\
AP Tours & 0.8933 & 0.7176 & 0.8113 & 0.8604 & 0.8740 & 0.8640 & 0.8650 & 0.8070 \\
Travelstore & 0.8458 & 0.8608 & 0.8898 & 0.8008 & 0.9180 & 0.8280 & 0.8210 & 0.8170 \\
Cosmos & 0.9115 & 0.8953 & 0.8755 & 0.9116 & 0.9040 & 0.9130 & 0.9030 & 0.8960 \\
Paneuropa & 0.8837 & 0.9036 & 0.8824 & 0.9029 & 0.9160 & 0.9230 & 0.9100 & 0.8120 \\
Bravatour & 0.8945 & 0.8963 & 0.9092 & 0.8852 & 0.8990 & 0.9020 & 0.8900 & 0.8721 \\
Entremares & 0.9070 & 0.9101 & 0.9304 & 0.8797 & 0.8800 & 0.8840 & 0.8750 & 0.8700 \\
Club Viajar & 0.7137 & 0.8862 & 0.9232 & 0.9389 & 0.9050 & 0.7250 & 0.8920 & 0.7950 \\
Portimar & 0.7031 & 0.7112 & 0.8751 & 0.8825 & 0.9100 & 0.7100 & 0.8950 & 0.6950 \\
Teles & 0.7884 & 0.7111 & 0.8780 & 0.9088 & 0.8720 & 0.7690 & 0.8490 & 0.7500 \\
ACP & 0.7954 & 0.7212 & 0.8946 & 0.9186 & 0.8680 & 0.7660 & 0.8500 & 0.7620 \\
Netviagens & 0.7059 & 0.7049 & 0.7060 & 0.8630 & 0.7110 & 0.7030 & 0.9300 & 0.7120 \\
Average & 0.8615 & 0.8476 & 0.8812 & 0.8905 & 0.8846 & 0.8586 & 0.8873 & 0.8506 \\
\hline & & & & & & & &
\end{tabular}

The Group variable appears to have a strong and significant impact on both productivity and efficiency. This finding seems to indicate that group membership benefits travel agents through better technological networking and more coherent management practices. In terms of foreign ownership, the variable does not seem to have any significant impact on both productivity and efficiency.

Table 7. Bootstrapped truncated regressions.

\begin{tabular}{|c|c|c|c|c|c|c|}
\hline Variable & Coefficient & $\begin{array}{l}\text { MI } \\
\text { Standard } \\
\text { error }\end{array}$ & $t$-Value & Coefficient & $\begin{array}{c}\text { Efficiency } \\
\text { Standard } \\
\text { error }\end{array}$ & $t$-Value \\
\hline Constant & $0.9875 * *$ & 0.0479 & 19.832 & $0.8907 * *$ & 0.1792 & 4.9759 \\
\hline Share & $1.8633 *$ & 0.9556 & 1.9498 & $0.1604 * *$ & 0.0386 & 4.1470 \\
\hline Group & $0.1899 * *$ & 0.0459 & 4.1372 & $0.0030 * *$ & 0.0010 & 3.0010 \\
\hline Foreign & 0.0352 & 0.1333 & 0.2640 & -0.0032 & 0.0048 & -0.6800 \\
\hline
\end{tabular}

Note: **Significant at the $5 \%$ confidence level; *significant at the $10 \%$ confidence level. 


\section{Managerial implications}

The results displayed by the Malmquist productivity scores in Table 3 indicated that Portuguese travel agents experienced an increase in productivity. The productivity fluctuated throughout the period, but generally it was consistently positive on average. Initially, this result was expected due to the intense competition in the market. If we consider the disentangling of the Malmquist productivity score between efficiency change and technological change, it is verified that the productivity change is due mainly to technological improvements (Table 4), which are attributed to investment allocation, while efficiency (Table 5) has decreased slightly. For some travel agents, efficiency also has decreased significantly.

As technical efficiency is attributed to management skills, this indicates that on this issue, productivity has not improved. This might be related to the low educational qualifications of many workers in this field. It is also clear that efficiency is particularly lower for smaller travel agents such as Teles and ACP, which usually have lower financial resources in comparison to larger agents. Further evidence on impact of size was provided from the second-stage regression of the paper, where it was clear that an increase in market share contributed positively to productivity and efficiency improvements. The literature discusses that small agents are at a disadvantage in this market, as they lack the financial and capital resources to absorb the discounts made by airlines.

In line with the impact of size, another important finding relates to the positive influence of group membership on productivity improvements. The existing literature has provided contradictory findings. A look at the early literature (for example, Porter, 1987; Rumelt, 1991; Markides, 1995; McGahan and Porter, 1997) indicates that most studies propose that group affiliated firms do not necessarily have more value and profit than non-group affiliated firms. Porter also tested this hypothesis on a sample of 33 large US companies and found that firm diversification did not necessarily create shareholder value. Recent studies tend, however, to propose different findings. Chu (2004), for example, tested this hypothesis on a sample of Taiwanese firms and indicated that group affiliation could be beneficial but success was highly dependent on the size of the group. Other studies (Ghemawat and Khanna, 1998; Khanna and Palepu, 2000) have also linked the success of a group affiliation to the type of market, where group affiliated firms tend to outperform non-group affiliated firms in emerging markets. Portugal, for example, is a perfect example of an emerging market. The economy is characterized by market failure caused by lack of financial and capital resources. In this context, a firm may be most profitable by joining a group, as it can benefit from the internal resources and reputation to make up for the external market failures (Khanna and Palepu, 2000). Equally, this will hold in the case of travel agents, especially as most Portuguese travel agents also suffer from small size and poor economies of scale.

What other strategies can be adopted by Portuguese travel agents to improve efficiency and productivity? As was mentioned before, the industry will face more intense competition and operational difficulties in the future, resulting mainly from the growing impact of online and direct bookings with travel and 
accommodation operators. IBISWorld (2009) discuss that in order to face competition, travel agents need to expand their corporate/business accounts, concentrate on inbound and outbound travel (away from domestic airline travel) and seek international expansion. A niche area such as cruising, which is growing rapidly, will also provide growth opportunities. Successful agents will need to link on to new technology to present and sell their products and continue to achieve volume sales on the packages developed. Currently, many Portuguese agents, especially those operating on a small scale, do not have websites or access to the Internet. This is a major concern and represents a potential loss of revenue. Apart from focusing mainly on ticketing, small Portuguese agents should offer other services such as hotel and car bookings or travel insurance. Currently, such offerings are restricted mainly to some large travel agents. Strategies for the way forward should also include the adoption of proactive measures that capitalize on the growth of demand for travel-related sporting and cultural events. Assistance to small agents should come from the Portuguese Ministry of Tourism by controlling the entrance of new agents in the market, as this increases competition and accordingly creates a major threat to the existence of the current agents. As mentioned before, group membership could also be a highly desired strategy for small agents.

Portuguese agents should focus on improving the skills of their employees. Fortunately, tourism organizations in Portugal are trying to assist agents. For instance, the Portuguese National Tourist Office has launched a new online training programme designed to transform agents into experts on the country and its tourist regions. Other assistance is also occurring in terms of marketing travel agents to international and domestic visitors.

\section{Conclusions}

This study has assessed the productivity and efficiency standing of Portuguese travel agents. A three-stage approach was used in the analysis. In the first stage, a bootstrapped Malmquist index approach was used to obtain estimates of total productivity growth, while in the second stage we derived estimates of technical efficiency scores using a bootstrapped DEA model. The determinants of productivity and efficiency variations between travel agents were then established in a third-stage truncated regression model. It was clear from the results that, on average, Portuguese travel agents have increased their productivity over the period of study. Factors which were found to be strong determinants of productivity and efficiency included market share and group ownership. The study also discussed the results in terms of the current characteristics of the Portuguese travel agent industry and highlighted areas for potential improvements.

\section{References}

Alamdari, F. (2002), 'Regional development in airlines and travel agents relationship', Journal of Air Transport Management, Vol 8, No 5, pp 339-348.

Anderson, R.I., Fish, M., Xia, Y., and Michello, F. (1999a), 'Measuring efficiency in the hotel industry: a stochastic frontier approach', International Journal of Hospitality Management, Vol 18, No 1 , pp 45-57. 
Anderson, R.I., Lewis, D., and Parker, M.E. (1999b), 'Another look at the efficiency of corporate travel management departments', Journal of Travel Research, Vol 7, No 3, pp 267-272.

Anderson, R.I., Fok, R., and Scott, J. (2000), 'Hotel industry efficiency: an advanced linear programming examination', American Business Review, Vol 18, No 1, pp 40-48.

Assaf, A. (2009), 'Accounting for size in efficiency comparisons of airports', Journal of Air Transport Management, Vol 15, No 5, pp 256-258.

Barros, C.P. (2006), 'Analysing the rate of technical change in the Portuguese hotel industry', Tourism Economics, Vol 12, No 3, pp 325-346.

Barros, C.P., and Dieke, P.U.C. (2007), 'Analyzing the total productivity change in travel agents', Tourism Analysis, Vol 12, No 1-2, pp 27-37.

Barros, C.P., and Dieke, P.U.C. (2008), 'Technical efficiency of African hotels', International Journal of Hospitality Management, Vol 27, No 2, pp 438-447.

Barros, C.P., and Matias, A. (2006), 'Assessing the efficiency of travel agents with a stochastic cost frontier: a Portuguese case study', International Journal of Tourism Research, Vol 8, No 5, pp 367379.

Bell, R.A., and Morey, R.C. (1995), 'Increasing the efficiency of corporate travel management through macro-benchmarking', Journal of Travel Research, Vol 33, No 3, pp 11-20.

Brown, J.R., and Ragsdale, C.T. (2002), 'The competitive market efficiency of hotel brands: an application of data envelopment analysis', Journal of Hospitality and Tourism Research, Vol 26, No 4, pp 332-360.

Buhalis, D. (2000), 'Marketing the competitive destination of the future', Tourism Management, Vol 21, No 1, pp 409-421.

Chu, W. (2004), 'Are group affiliated firms really more profitable than non-affiliated?', Small Business Economics, Vol 22, pp 391-405.

Coelli, T.J., Prasada Rao, D.S., O'Donnell, C.J., and Battese, G.E. (2005), An Introduction to Efficiency and Productivity Analysis, 2nd Edition, Springer, New York, 366 pp.

Fare, R., Grosskopf, S., and Lovell, C.A.K. (1994). Production Frontier, Cambridge University Press, Cambridge.

Frias, D., Rodriguez, M., and Castañeda, J.A. (2008), 'Internet vs. travel agencies on pre-visit destination image formation: an information processing view', Tourism Management, Vol 29, No 1, pp $163-179$.

Ghemawat, P., and Khanna, T. (1998), 'The nature of diversified business groups: a research design and two case studies', The Journal of Industrial Economics, Vol 1, pp 35-61.

IBISWorld (2009), Travel Agencies Service: Industry Report, IBISWorld, Melbourne.

Johns, N., Howcroft, B., and Drake, L. (1997), 'The use of data envelopment analysis to monitor hotel productivity', Progress in Tourism and Hospitality Research, Vol 3, pp 119-127.

Khanna, T., and Palepu, K. (2000), 'Is group affiliation profitable in emerging markets? An analysis of diversified Indian business groups', Journal of Finance, Vol 55, pp 867-891.

Köksal, C.D., and Aksu, A.A. (2007), 'Efficiency evaluation of A-group travel agents with data envelopment analysis (DEA): a case study in the Antalya region, Turkey', Tourism Management, Vol 28, No 3, pp 830-834.

Law, R., Law, A., and Wai, E. (2002), 'The impact of the Internet on travel agencies in Hong Kong', Journal of Travel and Tourism Marketing, Vol 11, No 2/3, pp 105-126.

McGahan, A.M., and Porter, M.E. (1997), 'How much does industry matter, really?', Strategic Management Journal, Vol 18, pp 15-30.

Markides, C.C. (1995), 'Diversification, restructuring and economic performance', Strategic Management Journal, Vol 16, pp 101-118.

Peypoch, N., and Solonandrasana, B. (2006), 'Technical efficiency in the tourism industry', Tourism Economics, Vol 12, No 4, pp 653-657.

Peypoch, N., and Solonandrasana, B. (2008), 'Aggregate efficiency and productivity analysis in the tourism industry', Tourism Economics, Vol 14, No 1, pp 45-56.

Porter, M.E. (1987), 'From competitive advantage to corporate strategy', Harvard Business Review (May-June), pp 43-59.

Reynolds, D. (2003), 'Hospitality-productivity assessment using data envelopment analysis', Cornell Hotel and Restaurant Administration Quarterly, Vol 44, No 2, pp 130-137.

Reynolds, D., and Thompson, F.M. (2007), 'Multiunit restaurant productivity assessment using three-phase data envelopment analysis', International Journal of Hospitality Management, Vol 26, No 1, pp 20-32. 
Rumelt, R.P. (1991), 'How much does industry matter?', Strategic Management Journal, Vol 12, pp $167-185$.

Simar, L., and Wilson, P.W. (1998), 'Sensitivity analysis of efficiency scores: how to bootstrap in non-parametric frontier models', Management Science, Vol 44, pp 49-61.

Simar, L., and Wilson, P.W. (1999), 'Estimating and bootstrapping Malmquist indices', European Journal of Operational Research, Vol 11, pp 459-471.

Simar, L., and Wilson, P.W. (2000), 'A general methodology for bootstrapping in non-parametric frontier models', Journal of Applied Statistics, Vol 27, pp 779-802.

Simar, L., and Wilson, P.W. (2007), 'Estimation and inference in two-stage, semi-parametric models of production processes', Journal of Econometrics, Vol 136, pp 31-64.

Tse, A.C. (2003), 'Disintermediation of travel agents in the hotel industry', International Journal of Hospitality Management, Vol 22, No 4, pp 453-460. 